\title{
Pengaruh Proses Rekrutmen (Porek) dan Seleksi terhadap Kinerja Karyawan PT. BANK MAYA PADA INTERNASIONAL, Tbk
}

\author{
Nurul Aisyah, SE, MM \\ Bina Sarana Informatika \\ Nurul.nly@bsi.co.id \\ Angelia Giovanni \\ Bina Sarana Informatika \\ angeliagiovanni9@gmail.com
}

\begin{abstract}
Abstrak
Sumber daya manusia ( SDM) merupakan suatu aset yang memegang peranan penting di dalam suatu perusahaan, karena manusia yang mengelola dan menjalankan kegiatan yang ada di dalam organisasi. Salah satu aspek yang berpengaruh dalam mencapai tujuan suatu perusahaan adalah rekrutmen dans eleksikerja, karena rekrutmen dan seleksi merupakan suatu kondisi yang menggerakkan manusia ke suatu tujuan tertentu. Rekrutmen dan seleksi kerja dapat bermanfaat bagi kinerja karyawan dan perusahaan.

Menggunakan metode deskriptif kuantitatif dengan menggunakan teknik sampel jenuh, jumlah responden sebanyak 50 responden dengan menggunakan SPSS versi 22. Dalam hasil penelitian penulis dapat diketahui, bahwa adanya hubungan rekrutmen dan seleksi terhadap kinerja yang sangat kuat yaitu sebesar $0,887(88,7 \%)$ adanya pengaruh rekrutmen dan seleksi terhadap kinerja. Besarnya angka koefisien determinasi 0,786 atau sama dengan $78,6 \%$, sedangkan sisanya yaitu 21,4\% (100\%-78,6\%) dijelaskan oleh faktor-faktor penyebab lainnya dan tingkat signifikan sebesar 0,000 maka $\mathrm{H}_{1}$ diterima, persamaan regresi signifikan, sehingga persamaan regresi yang dapat dibentuk yaitu: $\mathrm{Y}=7,722+0,802 \mathrm{X}$, oleh karena itu tingkat motivasi yang ada harus tetap dipertahankan dan harus lebih ditingkatkan lagi khususnya pada kinerja karyawan itu sendiri.
\end{abstract}

Kata Kunci Rekrutmen, Seleksi dan Kinerja Karyawan

Abstrak Human resources is an asset that plays an important role in a company, because humans who manage and run activities that exist within the organization. One of the most influential aspects in achieving the objectives of a company is recruitment and selection of work, because recruitment and selection is a condition that moves people to a particular destination. Recruitment and selection of work can benefit employee and company performance. 
method is the authors take descriptive quantitative by using the sample technique saturated, the number of respondents as much as 50 respondents using SPSS version 22. In the results of research authors can know, that the relationship of recruitment and selection of a very strong performance that is equal to 0.887 (89\%) the influence of recruitment and selection on performance. The amount of coefficient of determination 0,786 or equal to $78,6 \%$, while the rest is $21,4 \%(100 \%$ $-78,6 \%)$ explained by other causal factors and significant level of 0.000 then $H 1$ accepted, regression equation significant, so that regression equation that can be formed is: $Y=7,722+0,802 X$, therefore the existing level of motivation must be maintained and should be further improved especially in the employee's own performance.

Keywords Recruitment, Employee Selection and Performance

\section{PENDAHULUAN}

Pengelolaan Sumber Daya Manusia (SDM) merupakan hal yang penting dalam pencapaiaan tujuan. Umumnya pimpinan perusahaan mengharapkan kinerja yang baik dari masing - masing karyawan dalam mengerjakan tugas tugas yang diberikan oleh perusahaan. Perusahaan menyadari bahwa Sumber Daya Manusia (SDM) merupakan modal dasar dalam proses pembangunan perusahaan bahkan nasional, oleh karena itu kualitas SDM senantiasa harus dikembangkan dan diarahkan agar tercapainya tujuan yang telah ditetapkan oleh perusahaan

aktivitas-aktivitas manajemen sumber daya manusia ini terdiri dari : perencanaan sumber daya manusia, pengadaan, pengarahan, pengembangan, pemeliharaan, dan pemberhentian. Hal ini ditujukan agar perusahaan dapat mengelola sumber daya manusia yang baik secara efektif dan efisien.

PT. Bank Maya pada Internasional, Tbk merupakan perusahaan yang bergerak di bidang jasa perbankan, dimana Bank Maya pada merupakan salah satu Perusahaan Perbankan ternama di Indonesia. Sumber daya manusia yang handal dan kompeten merupakan faktor pengungkit untuk keunggulan bersaing PTBank MayapdaInternasiona, Tbk, sehingga pengembangan Kompetensi Sumber Daya Manusia merupakan salah satu faktor kunci keberhasilan untuk pencapaian visi dan misi perusahaan, Sejalan dengan visi, misi, dan strategi perusahaan untuk menjadi perusahaan kelas dunia di bidang jasa asuransian, perlu diterapkan upaya yang lebih fokus dalam pengembangan SDM secara konsisten dan terus menerus.

Pengelolaan sumber daya manusia sangat diperlukan untuk efektivitas sumber daya manusia dalam suatu organisasi. Tujuan dari hal tersebut adalah untuk memberikan kepada organisasi satuan kerja yang efektif untuk mencapai tujuan studi tentang manajemen perusahaan bagaimana seharusnya perusahaan dapat mengembangkan, menggunakan dan memelihara karyawan dalam kualitas dan kuantitas yang tepat

Oleh karena itu pihak manajemen perusahaan harus mampu memahami bagaimana cara terbaik dalam mengelola karyawan yang berasal dari latar belakang, keahlian, dan kemampuan yang berbeda-beda sehingga karyawan dapat bekerja sesuai dengan keahlian dan jenis pekerjaan yang diberikan. Penyusutan pegawai yang terjadi biasanya karena adanya pegawai yang memasuki masa pensiun, meninggal dunia atau dikeluarkan dari institusi karena melakukan pelanggaran tata tertib disiplin yang telah ditetapkan oleh PTBank Mayapada Internasional, Tbk. Oleh karena itu pegawai baru yang akan menggantikannya akan memiliki masa kerja yang berbeda-beda. Rekrutmen juga dapat dilakukan untuk menambah pegawai baru kedalam suatu satuan kerja yang kegiatannya menuntut aktivitas yang tinggi. Dalam PROSES REKRUTMEN (POREK) juga memerlukan adanya proses seleksi yang efektif, hal ini dilakukan untuk melakukan pemerataan pegawai sehingga kekuatan SDM yang dimiliki menjadi lebih seimbang. 
Berdasakan uraian diatas maka penulis mengambil judul : "Pengaruh PROSES REKRUTMEN (POREK) dan Seleksi Terhadap Kinerja KARYAWAN PT BANK MAYA PADA INTERNASIONAL, Tbk".

\section{TINJAUAN PUSTAKA}

\subsection{Rekrutmen}

\subsubsection{Pengertian Rekrutmen}

Berikut definisi rekrutmen menurut beberapa para ahli, sebagai berikut :

a. Menurut Mardianto (2014:8) diartikan sebagai suatu proses untuk mendapatkan calon karyawan yang memiliki kemampuan yang sesuai dengan kualifikasi dan kebutuhan suatu organisasi/perusahaan.

b. Menurut Naheed dan Amir (2012) rekrutmen merupakan proses dalam mencari orang-orang yang dinilai tepat untuk suatu pekerjaan. Setiap pekerjaan dalam bidang bisnis memerlukan kemampuan dan kualitas staff yang baik sebagai nilai tambah bagi perusahaan.

c. Menurut Omolo, Oginda, Oso (2012) rekrutmen merupakan pencarian kandidat karyawan melalui iklan dan metode lainnya, menyaring kandidat dengan wawancara dan tes. Kemudian dipilih berdsarkan hasil tes tersebut apakah mampu memenuhi peran baru mereka secara efisien.

d. Menurut Herman Sofyandi (2010:108) rekrutemen adalah serangkaian kegiatan yang dimulai ketika sebuah perusahaan atau organisasi memerlukan tenaga kerja dan membuka lowongan sampai mendapatkan calon karyawan yang diinginkan sesuai dengan jabatan atau lowongan yang ada..

\subsubsection{Penentuan Dasar Rekrutmen}

Proses Rekrutmen (POREK) (penarikan) saat ini memiliki beberapa istilah populer seperti: Job Analysis, Job Description, Job Specification, Job Evalution, dan Job Classification. Uraiannya adalah sebagai berikut :

1. Job Analysis (Analisis Jabatan)

Analisis jabatan merupakan prosedur untuk menentukan tanggung jawab dan persyaratan, keterampilan dari sebuah pekerjaan dan jenis orang yang akan dipekerjakan

2. Job Description (Uraian Jabatan)

Menurut Yoder (2010) mengatakan uraian jabatan adalah mengikhtisarkan fakta-fakta yang diberikan oleh analisis jabatan dalam susunan yang sistematis. Uraian jabatan merupakan garis-garis besar yang ditulis dan dimaksudkan untuk memberikan penjelasan tentang fakta-fakta yang penting dari jabatan yang diberikan.

3. Job Spesification (Persyaratan Jabatan)

Persyaratan jabatan adalah catatan mengenai syarat-syarat orang yang minimum harus dimiliki untuk menyelesaikan pekerjaan dengan baik (Moekijat : 2010)

4. Job Evalution (Penilaian Jabatan)

Menurut Moekijat (2010) mengatakan penilaian jabatan adalah penilaian kegiatan yang dilakukan guna membandingkan nilai dari suatu jabatan dengan nilai dar suatu jabatan lainnya.

5. Job Classification (Penggolongan Jabatan)

Penggolongan jabatan adalah pengelompokan jabatan-jabatan yang memiliki nilai yang sama (Moekijat : 2010)

\subsubsection{Penentuan Sumber-Sumber Rekrutmen}

Setelah diketahui spesifikasi jabatan atau pekerjaan karyawan yang diperlukan, mak harus ditentukan sumber-sumber penariakan calon karyawan.Sumber penarikan calon karyawan bisa berasal dari internal dan eksternal perusahaan.

\section{a. Sumber Internal}

Adapun kebaikan dari sumber internal adalah :

1. Tidak terlalu mahal.

2. Dapat memelihara loyalitas dan mendorong motivasi karyawan yangada.

3. Karyawan telah terbiasa dengan suasana dan budaya perusahaan.

Sedangkan kelemahan dari sumber internal yaitu : 
1. Pembatasan terhadap bakat-bakat.

2. Mengurangi peluang.

3. Dapat meningkatkan puas diri.

Adapun sumber-sumber internal melalui :

1. Penawaran terbuka untuk suatu jabatan (Job Posting Program) Rekrutmen terbuka ini merupakan sistem mencari pekerjaan yang memiliki kemampuan tinggi untuk mengisi jabatan yang kosong dengan memberikan kesempatan kepada semua karyawan yang berminat.

2. Perbantuan Pekerja (Departing Employees) Rekrutmen ini dapat dilakukan melalui perbantuan pekerja untuk suatu jabatan dari unit kerja lain.

\section{b. Sumber Eksternal}

Sumber-sumber eksternal berasal dari :

1. Kantor penempatan tenaga kerja

2. Lembaga-lembaga pendidikan

3. Referensi karyawan atau rekan

4. Serikat-serikat buruh

5. Pencangkokan dari perusahaan lain

6. Nepotisme atau leasing

7. Pasar tenaga kerja dengan memasang ikln melalui media massa

8. Dan sumber-sumber lainnya.

\subsubsection{Metode-Metode Rekrutmen}

Metode yang diterapkan pada PROSES REKRUTMEN (POREK)akan berpengaruh sangat besar terhadap banyaknya lamaran yang masuk ke dalam perusahaan. Metode calon karyawan baru, dibagi menjad metode terbuka dan metode tertutup.

\section{Metode Terbuka}

Metode terbuka adalah dimana rekrutmen diinformasikan secara luas dengan memasang iklan pada media masa baik cetak atau elektronik, ataupun dengan cara dari mulut ke mulut (kabar orang lain) agar tersebar ke masyarakat luas. Dengan metode terbuka ini diharapkan dapat menarik banyak lamaran yang masuk, sehingga kesempatan untuk mendapatkan karyawan yang qualified menjadi lebih besar.

\section{Metode Tertutup}

Metode tertutup yaitu dimana rekrutmen diinformasikan kepada para karyawan atau orang tertentu saja. Akibatnya lamaran yang masuk relatif sedikit, sehingga kesempatan untuk mendapatkan karyawan yang baik akan semakin sulit.

\subsection{Seleksi}

\subsubsection{PengertianSeleksi}

Berikut definisi seleksi yang dikemukakan oleh beberapa ahli,tetapi maksud dan hakikatnya adalah sama.

a. Menurut Hasibuan (2011:177) Seleksi adalah suatu kegiatan pemilihan dan penentuan pelamar yang diterima atau yang ditolak untuk menjadi karyawan perusahaan itu.

b. Menurut Rivai (2011 : 159) Menjelaskan bahwa seleksi adalah kegiatan dalam manajemen SDM yang dilakukan setelah PROSES REKRUTMEN (POREK)selesai dilaksanakan. Hal ini berati telah terkumpul sejumlah pelamar yang memenuhi syarat untuk kemudian dipilih mana yang dapat ditetapkan sebagai karyawan dalam suatu perusahaan. Proses pemilihan ini yang dinamakan dengan seleksi.

c. Menurut T. Hani Handoko (2010:85) Proses seleksi adalah serangkaian langkah kegiatan yang digunakan untuk memutuskan apakah pelamar diterima atau tidak.

d. Menurut I Komang Ardana (2012:69)

Seleksi tenaga kerja adalah suatu kegiatan untuk menentukkan dan memilih tenaga kerja yang memenuhi syarat-syarat yang telah ditetapkan oleh perusahaan. 


\subsubsection{Tujuan Proses Seleksi}

Menurut Drs. Malayu S.P. Hasibuan (2011:49) seleksi penerimaan karyawan dalam suatu perusahaan untuk bertujuan mendapatkan hal - hal berikut :

1. Karyawan yang qualifieddan potensial

2. Karyawan yang jujur dan berdisplin

3. Karyawan yang cakap dengan penempatan yang tepat

4. Karyawan yang terampil dan bersemangat dalam bekerja

5. Karyawan yang memenuhi persyaratan undang - undang perburuhan

6. Karyawan yang dapat bekerja sama baik verbal maupun horizontal

7. Karyawan yang dinamis da kreatif

8. Karyawan yang inovatif dan bertanggung jawab sepenuhnya

9. Karyawan yang loyal dan berdedikasi tinggi

10. Mengurangi tingkat absensi dan turn over karyawan.

11.

\subsubsection{Metode Seleksi}

Metode seleksi karyawan yang dilaksanakan perusahaan maupun organisasi social dalam penerimaan karyawan baru dikenal dengan dua cara yaitu :

1. Metode Non ilmiah

Seleksi dengan nonilmiah adalah seleksi yang dilaksanakan tidak didasarkan kepada kriteria, standar, atau spesifikasi kebutuhan nyata pekerjaan atau jabatan, tetapi hanya didasarkan kepada perkiraan dan pengalaman saja. Berikut ada beberapa unsur-unsur yang diseleski biasanya hanya meliputi hal-hal berikut :

1. Surat lamaran bermaterai atau tidak

2. Ijazah sekolah dan daftar nilainya

3. Surat keterangan pekerjaan dan pengalaman

4. Referensi atau rekomendasi dari pihak yang dapat dipercaya

5. Wawancara langsung dengan pelamar bersangkutan

6. Penampilan dan keadaan fisik(cantik atau gantengnya) pelamar

7. Keturunan daripelamar bersangkutan

8. Tulisan pelamar

Seleksi nonilmiah kurang dapat dipertanggungjawabkan karena sering memperoleh karyawan baru yang tidak cakap menyelesaikan pekerjaannya, bahkan menimbulkan kesulitan-kesulitan bagi perusahaan, karena tulisan yang baik, tampang yang cakap, bicara yang lancar belum tentu terampil dan bergairah bekerja. Sebaliknya seseorang yang mempunyai tampang yang kurang cakap, tulisan yang tidak baik, dan bicara yang kurang lancar, bisa jadi lebih terampil, bergairah, kreatif, dan loya terhadap pekerjaan.

2. Metode Ilmiah

Seleksi dengan metode ilmiah adalah seleksi yang didasarkan kepada job specification dan kebutuhan nyata jabatan yang akan diisi, serta berpedoman kepada kriteria dan standar-standar tertentu. Job specification adalah surat pernyataan tertulis yang berisi tentang keterampilan, kemampuan dan kualifikasi yang harus dimiliki oleh seseorang yang akan melaksanakan jabatan atau pekerjaan tertentu secara efektif. Job Descriptonadalah surat pernyataan tertulis yang berisi tentang berbagi tugas dan tanggungjawab yang harus dilakukan oleh seseorang yang memangku jabatan tertentu, kondisi kerja, peralatan dan material serta informasi yang akan digunakan untuk melaksanakan pekerjaan tersebut.

Seleksi metode ilmiah merupakan pengembangan seleksi nonilmiah dengan mengadakan analisis cermat tentang unsur-unsur yang akan diseleksi supaya diperoleh karyawan yang kompeten dengan penempatan yang tepat. Seleksi ilmiah hendak dilaksanakan dengan cara-cara berikut : 
1. Metode kerja yang jelas dan sistematis

2. Berorientasi kepada prestasi kerja

3. Berorientasi kepada kebutuhan riil karyawan

4. Berdasarkan kepada job analysis dan ilmu sosial lainnya

5. Berpedoman kepada undang-undang perburuhan.

Dengan seleksi ilmiah diharapkan akan diperoleh karyawan yang qualified dengan penempatan yang tepat. Sehingga pembinaan dan pengembangannya relatif lebih mudah.

\subsection{Kinerja}

\subsubsection{Pengertian Kinerja}

Suatu organisasi perusahaan didirikan karena mempunyai tujuan tertentu yang ingin dan harus dicapai. Dalam mencapai tujuannya setiap organisasi di pengaruhi perilaku organisasi. Salah satu kegiatan yang paling lazim di lakukan dalam organisasi adalah kinerja karyawan, yaitu bagaimana ia melakukan segala sesuatu yang berhubungan dengan sesuatu pekerjaan atau peranan dalam organisasi. Pengertian kinerja atau performance merupakan gambaran mengenai tingkat pencapaian pelaksanaan suatu program kegiatan atau kebijakan dalam mewujudkan sasaran, tujuan visi dan misi organisasi yang di tuangkan melalui perencanaan strategi suatu organisasi. Arti kata kinerja berasal dari taka-kata job performance dan di sebut juga actual performance atau prestasi kerja atau prestasi sesungguhnya yang telah di capai oleh seseorang kariyawan.

Berikut definisi rekrutmen menurut sebagai berikut :

a. Menurut Moeheriono (2012;95) yaitu Kinerja atau Performance merupakan gambaran mengenai tingkat pencapaian pelaksanaan suatu program kegiatan atau kebijakaan dalam mewudujkan sasaran, tujuan, visi, dan misi organisasi yang dituangkan melalui perencanaan strategis suatu organisasi.

b. Menurut Abdullah (2014:3)) memberikan pengertiaan bahwa kinerja merupakan hasil pekerjaan yang mempunyai hubungan kuat dengan tujuan strategis organisasi, kepuasan konsumen dan memberikan kontribusi ekonomi.

c. Menurut Foster dan Seeker dalam Widodo (2015:131) menjelaskan bahwa Kinerja adalah hasil yang dicapai seseorang menurut ukuran yang berlaku untuk pekerjaan yang bersangkutan.

d. Menurut Mangkunegara (2014:9) "Kinerja karyawan adalah hasil kerja secara kualitas dan kuantitas yang dicapai oleh seseorang karyawan dalam melaksanakan tugasnya sesuai dengan tanggung jawab yang diberikan kepadanya".

Berdasarkan beberapa definisi mengenai kinerja organisasi diatas, dapat ditarik kesimpulan bahwa kinerja organisasi merupakan hasil kerja organisasi ataupun gambaran mengenai apakah suatu organisasi telah dapat melaksanakan kegiatan/kebijakan sesuai dengan visi dan misi yang telah dibuat oleh organisasi

\subsubsection{Tujuan Pengukuran kinerja}

Pengukuran kinerja menurut Mardiasmo dalam Sinambela (2012: 187) mempunyai tiga tujuan, yaitu:

1. Membantu memperbaiki kinerja agar kegiatan terfokus pada tujuan dan sasaranprogram unit kerja.

2. Pengalokasian sumber daya dan pembuatan keputusan.

3. Mewujudkan pertanggung jawaban publik dan memperbaiki komunikasi kelembagaan.

\subsubsection{Pengukuran Kinerja}

Gary Dessler dalam Pasolong (2013: 182) menyatakan bahwa penilaian kinerja adalah merupakan upaya sistematis untuk membandingkan apa yang dicapai seseorang dibandingkan dengan standar yang ada. Tujuannya, yaitu untuk mendorong kinerja seseorang agar bisa berada di atas rata-rata.

Dari pendapat diatas dapat disimpulkan bahwa pengukuran kinerja adalah menilai hasil kerja suatu organisasi publik. Penilaian hasil kerja tersebut untuk melihat apakah hasil yang dicapai oleh suatu organisasi publik telah sesuai dengan visi dan misi yang telah ditetapkan oleh organisasi publik tersebut 


\section{METODE PENELITIAN}

Menggunakan metode deskriptif kuantitatif dengan menggunakan teknik sampel jenuh, jumlah responden sebanyak 50 responden dengan menggunakan SPSS versi 22.

\section{HASIL DAN PEMBAHASAN}

\section{Uji Koefisien Korelasi}

Untuk mengetahui besarnya hubungan antara rekrutmen dan seleksi terhadap kinerja, maka dapat digunakan rumus koefisien korelasi sebagai beriut:

$$
\begin{aligned}
& r x y=\frac{n \sum x_{i} y_{i}-\left(\sum x_{i}\right)\left(\sum y_{i}\right)}{\sqrt{\left(n \sum x_{i}^{2}-\left(x_{i}\right)^{2}\right)\left(n \Sigma y_{i}^{2}-\left(y_{i}\right)^{2}\right)}} \\
& r x y=\frac{50.69872-(1852)(1878)}{\sqrt{\left(50.68984-(1852)^{2}\left(50.70856-(1878)^{2}\right)\right.}} \\
& r x y=\frac{3493600-3478056}{\sqrt{(3449200-3429904)(3542800-3526884)}} \\
& r x y=\frac{15544}{\sqrt{(19296)(15916)}} \\
& r x y=\frac{15544}{\sqrt{307115138}} \\
& r x y=\frac{15544}{17524} \\
& r x y=0,887
\end{aligned}
$$

Berdasarkan Tabel II.4 pedoman untuk memberikan interprestasi terhadap koefisien maka koefisien korelasi yang ditemukan sebesar 0.887 termasuk pada kategori sangat kuat.Jadi terdapat hubungan yang sangat kuat antara rekrutmen dan seleksi terhadap kinerja karyawan pada PT Bank Mayapada Internasional Tbk Jakarta Pusat.

Untuk mengetahui hasil koefisien korelasi signifikan atau tidak, perlu dibandingkan dengan $r$ table. Dengan uji 2 (dua) arah tingkat kesalahan 5\% N=50/df+48, maka harga table $r=0.279$. Ternyata harga $r$ hitung lebih besar dari $\mathrm{r}$ table sehingga H1diterima dah $\mathrm{H} 0$ ditolak.Jadi kesimpulannya adalah adanya hubungan positif dan nilai keofisien korelasi antara rekrutmen dan seleksi terhadap kinerja karyawan sebesar 0,887 .

Berdasarkan table II.5 uji koefisien dapat diketahui bahwa nilai signifikan senilai $0.80<1.000$ maka keputusan H1diterima, dapat disimpulkan bahwa terdapat hubungan anatar rekrutmen dan seleksi terhadap kinerja karyawan.

Tabel III.31

\section{Uji Koefisien Korelasi}




\begin{tabular}{|c|c|c|c|}
\hline \multicolumn{4}{|c|}{ Correlations } \\
\hline & & REKRUTMEN\& SELEKSI & KINERJA \\
\hline \multirow[t]{3}{*}{ REKRUTMEN \& SELEKSI } & Pearson Correlation & ter &, $887^{* *}$ \\
\hline & Sig. (2-tailed) & & .000 \\
\hline & $\mathrm{N}$ & 50 & 50 \\
\hline \multirow[t]{3}{*}{ KINERJA } & Pearson Correlation & $887^{*}$ & 1 \\
\hline & Sig. (2-tailed) & .000 & \\
\hline & $\mathrm{N}$ & 50 & 50 \\
\hline
\end{tabular}

**. Correlation is significant at the 0.01 level (2-tailed).

Sumber: data SPSS yang diolah, 2017

Berdasarkan Tabel II.5 Koefisien Korelasi dapat diketahui bahwa atau nilai R sebesar 0,887, dapat diartikan bahwa hubungan rekrutmen dan seleksi terhadap kinerja memiliki hubungan yang sangat kuat dan searah karena bernilai positif.

\subsubsection{Uji Koefesien Determinasi}

Koefesien Determinasi dihitung untuk mengetahui sebarapa besar pengaruh PROSES REKRUTMEN (POREK)dan seleksi terhadap kinerja karyawan, untuk itu dipakai formula sebagai berikut :

Perhitunngan Koefisien Determinasi sebagai berikut:

$$
\begin{aligned}
\mathrm{KD} & =\mathrm{r}^{2} \times 100 \% \\
& =0,887^{2} \times 100 \% \\
& =0,786769 \times 100 \% \\
& =0,786769 \% \\
= & 78,6 \% \text { (dibulatkan) }
\end{aligned}
$$

Berdasarkan dari hasil perhitungan yang diperoleh dapat disimpulkan bahwa pengaruh PROSES REKRUTMEN (POREK)dan seleksi terhadap kinerja karyawan sebesar 78,6\% dan sisanya 21,4\% dipengaruhi faktor lainnya.

Tabel III.32

Uji Model Summary

\begin{tabular}{lcrrr}
\hline \multicolumn{5}{c}{ Model Summary } \\
\hline \multicolumn{5}{c}{} \\
Model & $\mathrm{R}$ & R Square & Adjusted R Square & Std. Error of the Estimate \\
\hline 1 &, $887^{\mathrm{a}}$ & .787 & .782 & 1.30947 \\
\hline a. Predictors: (Constant), KINERJA \\
\hline \multicolumn{3}{l}{ Sumber: data SPSS yang diolah, 2017 } \\
\hline
\end{tabular}

Berdasarkan Tabel III.30 Model Summary dapat diketahui bahwa nilai R Square sebesar 0,787 atau 78,6\% artinya rekrutmen dan seleksi dipengaruhi oleh kinerja, sisanya 21,4\% dipengaruhi faktor lain seperti kedisiplinan dan insentif. 


\subsubsection{Uji Persamaan Regresi}

Persamaan Regresi digunakan untuk memprediksikan pengaruh PROSES REKRUTMEN (POREK)dan seleksi terhadap kinerja karyawan. Adapun perhitungan persamaan regresi adalah sebagai berikut:

Perhitungan Persamaan Regresi Linear Sederhana:

$$
\mathrm{Y}=\mathrm{a}+\mathrm{bX}
$$

Berdasarkan perhitungan tersebut, persamaan regresi yang linear sederhana yaitu :

$\mathrm{Y}=\mathrm{a}+\mathrm{bX}$

$$
\mathrm{Y}=\mathrm{a}+\mathrm{bX}
$$

$$
\begin{aligned}
& \mathrm{a}=(\Sigma \mathrm{Y})\left(\sum \mathrm{X}^{2}\right)-(\Sigma \mathrm{X})\left(\sum \mathrm{XY}\right) \\
& \mathrm{n} \Sigma \mathrm{X}^{2}-(\Sigma \mathrm{X})^{2} \\
& =\frac{(1878)(68984)-(1852)(69872)}{50(68984)-(1852)^{2}} \\
& =\frac{129551952-129402944}{3449200-3429904} \\
& =\frac{149000}{19296} \\
& =7,7218 \\
& =7,722 \\
& \mathrm{~b}=\frac{n \Sigma X Y-(\Sigma X)(\Sigma Y)}{n \Sigma X^{2}-(\Sigma X)^{2}} \\
& =\frac{50.69872-(1852)(1878)}{50.68984-(1852)^{2}} \\
& =\frac{3493600-3478056}{3449200-3429904} \\
& =\frac{15544}{19296} \\
& =0,805
\end{aligned}
$$


Berdasarkan perhitungan tersebut, persamaan regresi yang linear sederhana yaitu :

$\mathrm{Y}=\mathrm{a}+\mathrm{bX}$

$Y=7,722+0,805 X$

Hal ini menunjukkan bahwa:

$\mathrm{a}=7,722$ artinya jika $\mathrm{X}=0$ atau tanpa ada rekrutmen dan seleksi maka kinerja sebesar 7,722

$\mathrm{b}=0.805$ artinya jika $\mathrm{X}$ dinaikan 1 angka atau setiap kenaikan rekrutmen dan seleksi sebesar 1

maka akan menaikan kinerja karyawan sebesar 9,527.

Berdasarkan perhitungan persamaan regresi menggunakan SPSS 22 adalah:

\section{Tabel III.33}

\begin{tabular}{|c|c|c|c|c|c|}
\hline \multicolumn{6}{|c|}{ Coefficients $^{\mathrm{a}}$} \\
\hline \multirow[b]{2}{*}{ Model } & \multicolumn{2}{|c|}{ Unstandardized Coefficients } & Standardized Coefficients & \multirow[b]{2}{*}{$\mathrm{t}$} & \multirow[b]{2}{*}{ Sig. } \\
\hline & B & Std. Error & Beta & & \\
\hline 1 (Constant) & 7,722 & 2,249 & & 3,434 &, 001 \\
\hline REKRUTMEN \& SELEKSI &, 806 &, 061 & 887 & 13,307 &, 000 \\
\hline
\end{tabular}

Berdasarkan table SPSS diatas dapat diperoleh persamaan regresi yaitu:

$\mathrm{Y}=7,722+0,805 \mathrm{X}$

Dimana:

$\mathrm{Y}=$ Kinerja

$\mathrm{X}=$ Rekrutmen dan Seleksi

Artinya jika $X=0$ atau tanpa ada rekrutmen dan seleksi maka kinerja sebesar 7,722 dan jika $X$ dinaikan 1 angka atau setiap kenaikan rekrutmen dan seleksi sebesar 1 maka akan menaikan kinerja karyawan sebesar 9,527.

\section{PENUTUP}

\section{Kesimpulan}

Berdasarkan hasil penelitian bahwa

1. Hasil Analisis Koefisien Korelasi pada PT Bank Maya pada Internasional Tbk Jakarta Pusat, didapatkan nilai $\mathrm{r}$ sebesar 0,887 atau 88,7\% yang mempunyai arti hubungan sangat kuat antara variabel independent (RekrutmendanseleksiKerja) dengan variabel dependent (Kinerja Karyawan).

2. Hasil Koefisien Determinasi didapatkan nilai sebesar 0,786 atau 78,6\%. Hal ini berarti rekrutmendanseleksi kerja mempengaruhi kinerja karyawan sebesar 78,6\%dan 21,4\% dipengaruhi oleh faktor lain, seperti (kedisiplinan dan insentif).

3. Hasil Analisis Koefisien Regresi Sederhana diperoleh persamaan $Y=7,722+0,805$ X yang menunjukan bahwa tanpa adanya rekrutmendanseleksi, maka hasil kinerja sebesar 7,722 dan jika $X$ naik atau turun 1 angka atau jika rekrutmendanseleksi dinaikan atau diturunkan 1\% maka akan menaikan atau menurunkan kinerja sebesar 9,527. 


\section{Daftar Pustaka}

Dessler, Gary. 2013. Manajemen Sumber Daya Manusia Edisi Kesepuluh. Jakarta. PT. Indeks.

Handoko, THani. 2010. Manajemen personalia dan Sumber Daya Manusia edisi 2. Yogyakarta: BPFE.

Hasibuan, Malayu. 2017. Manajemen Sumber Daya Manusia. Jakarta: Bumi Askara.

Mangkunegara, Anwar Prabu. 2014. Evaluasi Kinerja SDM. Bandung: PT RefikaAditama.

Sofyandi, Herman. 2010. Manajemen Sumber Daya Manusia.Yagyakarta. Graha Ilmu.

Ulfah, Rasima. 2016. Peranan Motivasi Kerja Terhadap Kinerja Karyawan Pada PT MustikaRatu Tbk Jakarta Timur. Depok: BSI Margonda

Widodo, Eko Suparno. 2015. Manajemen Pengembangan Sumber Daya Manusia. Yogyakarta: PUSTAKA PELAJAR.

Wulandari, Retno. 2017. Pengaruh Motivasi Terhadap Kinerja Karyawan Pada PT PLN (PERSERO) Distribusi Jawa Barat Area Depok: Depok. BSI Margonda. 